\section{AEROMEDICAL GRASHES IN THE UNITED STATES: \\ AN EPIDEMIC OF RECKLESSNESS OR THE COST OF DOING BUSINESS?}

\author{
Frank J. Baker, M.D. and Mary Juric, R.N., \\ Chicago, Illinois, U.S.A.
}

In the past two years there have been 44 crashes involving aeromedical aircraft with 34 associated deaths. We review the probable cause and associated circumstances surrounding these crashes. Specific recommendations regarding flight conditions and pilot judgment are made. The importance of establishing and adhering to flight minimums is emphasized.

\section{BLOOD ALCOHOL CONCENTRATIONS AND CHARACTERISTICS OF HOSPITALIZED MVA PATIENTS}

Evelyn Vingilis, M.D., C.B. Liban, B.Sc., B. Kapur, Ph.D., H. Blefgen, B.Sc., E. Larkin, Ph.D., R.Y. McMurtry, M.D., B. McLellan, M.D., W. Nelson, Ph.D. and M. Macartney-Filgate, Ph.D., Toronto, Ontario, Canada

Alcohol is a major factor in MVA fatalities in the industrialized world. In Canada, about $50 \%$ of all drivers killed had been drinking. Unfortunately, we have no good comparative figures for non-fatal injuries. What few studies are available, have major methodological problems such as high percentages of nonrespondents. Because of the dearth of information available on MVA injuries, the Ontario Sunnybrook Medical Centre Trauma Unit and the Addiction Research Foundation have embarked on a large-scale study on trauma victims. The purposes of the study are threefold: 1) to examine in a systematic way the injuries, recovery process and the factors such as blood alcohol levels (BACs), etc., that are related to injury severity and recovery; 2 ) the psychosocial characteristics of trauma victims; and 3) the longterm consequences of trauma on the victims. Preliminary findings from the first part of the study will be the focus of this presentation. Our paper will offer data on: 1) demographic characteristics; 2) injury severity and recovery ratings; and 3) BACs of all trauma victims admitted to the Sunnybrook Medical Centre
Trauma Unit over a 6 month period. For example, of the approximately 200 MVA trauma admissions, $40 \%$ tested BAC positive, with the summer months representing the higher levels of positive BACs. The relationships among the variables will be highlighted.

\section{BLUNT CHEST TRAUMA IN THE ELDERLY}

\author{
Robert M. Shorr, M.D., Matthew C. Indeck, M.D., \\ Michael D. Crittenden, M.D., \\ Susan L. Hartunian, M.D., \\ Aurelio Rodriguez, M.D. and \\ R Adams Cowley, M.D., \\ Los Angeles, California, U.S.A.
}

Twenty-five percent of the 140,000 annual civilian trauma deaths result from chest trauma. During a three year period, 515 patients presented with blunt chest trauma and within this group, 45 patients (8.7\%) were 65 years of age or greater. We present an analysis on the injury pattern, morbidity and mortality in this unique and growing trauma population.

The mean age of the group was 73.1 years. Mechanisms of injuries included motor vehicles, pedestrians struck by motor vehicles and falls. Fractures of the bony thorax comprised the largest single group of thoracic injuries with 36 fractures occurring either singly or in combination with other fractures. Other injuries included hemo-pneumothoraces (14 pts), flail chest (5 pts), pulmonary contusions (4 pts), cardiac contusions ( $2 \mathrm{pts})$, aortic rupture ( $2 \mathrm{pts})$, and ruptured diaphragms (1 pt). Eight-four patitients presented with one or more extra thoracic injuries. The overall morbidity was $55.6 \%$ and this was significantly higher $(p=.05)$ than the observed morbidity in the non-elderly group. Seventeen elderly patients died for a mortality of $37.7 \%$ which was also significantly increased when compared to the non-elderly group $(p=.001)$.

We conclude that blunt chest trauma in the elderly has a higher morbidity and mortality when compared to other patient populations. We attempt to generate a high risk patient profile within this group and make certain recommendations to decrease morbidity and mortality. With the increasing number of elderly persons in the world, it is important to recognize this group as a unique patient population. 